INTERNATIONAL DESIGN CONFERENCE - DESIGN 2018

https://doi.org/10.21278/idc.2018.0344

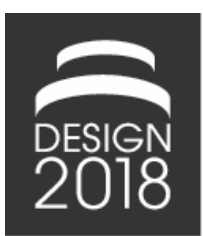

\title{
ADDRESSING TEAM BASED INNOVATION FOR SMALL FIRMS - CREATE, BUILD, TEST \& LEARN
}

\author{
J. Lugnet, J. Wenngren and Å. Ericson
}

\begin{abstract}
The Create-Build-Test-Learn supports toolbox for engineering concept development motivates not only experimentation, but also instils design thinking in teams. By offering tools and methods for reconstruction of the design challenge, the approach prevents teams to jump into a solution too quickly. When using prototyping as a team resource, reframing of the problem becomes part of the process, ensuring that efforts are put on solving the right problem. The article describes the contents of the toolbox as well as exemplifies how to use it. CBTL has been designed in particular to support SMEs.
\end{abstract}

Keywords: small and medium size enterprise (SME), teamwork, prototyping, early design phase, conceptual design

\section{Introduction}

Discovering and developing ideas to successful products on a market is a deliberate act not easily managed and executed. The design discipline has for this reason been promoting numerous development models to guide the developers throughout the process from an idea to the launch of a product. A development process is a guide for a company to manage resources and direct focus. For many firms', prescribed processes are a necessity that is constantly used and improved. Larger companies, may often have a specific department for research and innovation, which takes care of advances in technology and propose innovative new products or services. Utilizing a described process for how to conduct work may be a question of resources, for instance people and time, but also other factors play in. For many small and medium sized enterprises (SMEs) it is also a question of motivation and attitude (Örtqvist, 2015). Nonetheless, since many product development processes are addressing larger organisations one implication is that theories in engineering design have practical shortcomings to support SMEs (Löfqvist, 2014). SMEs often have unique possibilities due to being flexible and quicker than larger companies This means that they have better opportunities to fill the market gaps that other companies miss (Christensen et al., 2015). One risk, by basing development activities on craftsmanship, as is often the case in SMEs, can be that the cost for such procedures become high and that they most likely neglect to include radical innovation and game changing solutions. On the one hand, SMEs flexibility in terms of ability to quick adaptation and change of direction can potentially challenge established traditional businesses by disruptive innovation processes. Disruptive innovation in its early stages mean that a firm actually are capable to target overlooked markets and customers just because of their lower gross margins, smaller markets and simpler products (Christensen et al., 2015). Yet, many SMEs have limited knowledge and experience of innovation oriented development processes, although it is one core capability to address changing markets more coherently (Cantamessa, 2005). One essential skill of a disruptive approach is although that the design team possesses the ability to problematize the initial perception of a design challenge and also its embryonic concepts (e.g. Wenngren, 2016). For concept 
development, this suggests that thoughts, ideas and solutions that are bundled into a first version of a product should be confronted in a systematic way. Those initial concepts manifest the different design alternatives, and if not reflected on they become a hinder for innovation and new types of solutions. Typically, SMEs cannot allocate resources in a team to investigate alternative solutions for new products and markets. They could, instead, seek external support, for example in applied research projects.

This paper describes the rationale for the development of a supports toolbox, called CBTL-Create, Build, Test, Learn, and a description of how it is facilitated to sustain innovation among SMEs. This is done because our studies in previous research projects clearly indicated that SMEs are experiencing challenges in turning ideas into concepts, and also that there is a lack of awareness of basic development models and descriptions. An idea, in this case, can be described as an initial thought or impression, while it needs to be further elaborated and improved. A concept, in this case, consists of an assembly of ideas which convey how to solve a certain identified problem. The activities of investigating, analysing and synthesising are part of the process of turning ideas into concepts. Such exploratory activities are rarely part of development processes for SMEs as they, in this case, mostly deliver an order based on a specification from a customer. Simply, models adapted to SMEs' particular contexts and businesses seem to be delimited (Löfqvist, 2014), therefore a proposal of a format for innovation clinics, e.g. experimental and learning workshops could better assimilate such actions into the development strategies of those SMEs.

\section{Team-based innovation}

Engineering design processes typically start with a defined problem, about which the developers should gather more information around. Based on this, they should generate a number of solutions, analyse and select the candidate one, which should then be tested and implemented (e.g. Khandani, 2005). A framework based on the steps design, build and test provide direction, while they could also correspond to the iterative learning cycle of define, prototype and evaluate (see Figure 1). Both types have been proposed to highlight engineering design thinking (e.g. Sheppard et al., 1997; Dubberly, 2004). Prototyping can be observed in several models presented in engineering design literature, for example to improve communication in team-based innovation (Bergström, 2009), or to highlight that innovation activities are best conducted in teams (e.g. Brown, 2008; Steinert and Leifer, 2012).

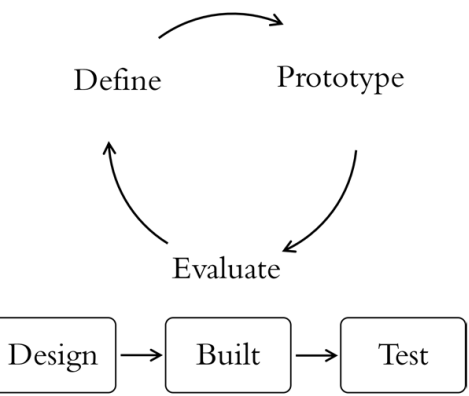

Figure 1. Design, build, test and define, prototype, evaluate framework (adapted from Dubberly, 2004)

Those innovation teams are suggested to be cross-disciplinary thus increasing differences in perspectives, and consequently also increasing uncertainty. Even professionals have to train to manage such ambiguous practices (Dym et al., 2005).

Problems occurring in concept development are typically related to diverging and converging activities (e.g. Dubberly, 2004; Jacoby and Rodriguez, 2007). This is a situation in which the developers find themselves having too narrow or too broad views of the problem. This is causing a situation where a narrow-minded tendency results in an inability to rethink and test the design brief and a too broad makes it hard to concretize the ideas into a candidate concept (e.g. Cox et al., 2014). Different types of communicative prototyping are suggested to unleash the team's creativity and innovation capabilities, e.g. rough visual and interactive representations by using available every day props (Brown, 2008), or low-fidelity sketches (Ericson et al., 2012). Early prototyping in concept development, should support 
learning-by-doing and provide simplicity and swiftness when communicating ideas and concepts (Howard et al., 2008) that all should improve the outcome (Yang, 2005). Based on these suggestions, a useful supports toolbox should sustain the transformation of ideas and concepts into physical expressions, thus enabling the team to iteratively confront their perceptions and create new solutions.

\section{Background and lessons learned}

The empirical background data in this study originates from a longitudinal research approach, where the results comes from the design and use of several innovation tools and methods over time. These lessons learned have led the development of a the CBTL toolbox for SMEs. The research started in the beginning of 2000, and then the topic was to provide innovation support to an engineering design course. The course was distributed, and the students worked in global design teams. The type of support developed here was a deck of creative method cards, these were grounded in previous studies of problem-based project courses. The method cards were a response to the findings that students in the project courses did not have any support for facilitation of their own processes and often they were asking for methods to use. The method cards provide a number of creative methods, but also guidelines for when to apply them. Next iteration in the development of innovation support resulted in a facilitated workshop format that, since then, have been used in different industrial contexts and organisations as well as in other courses at several universities. The format has been refined and adapted to fit different problem owners, one such adaptation was to support large multinational company, for which 8 workshops have been done. These workshops helped to further improve the facilitator role as an external resource for the workshop participants and project teams (Ericson and Törlind, 2013). Also, 25 innovation change facilitators were trained at one of these large manufacturing company, this was done in order to reach out to larger part of the organisation, e.g., geographically situated in Germany, France, South Korea, USA and Sweden. The goal for the company was to equip the staff with innovation support and through geographical spread also ensure that the personnel could share it further.

The learnings from those studies inspired the composition of a small booklet (Bergström et al., 2010) of a four-step process to support creative concept development. The iterative process consists of inspiration, immersion, ideation and implementation, i.e., first understand and empathise with people in common and potential users, followed by analysis and formalisation of the observations and talks with people, and after that the generation of ideas and making combined concepts of those ideas. The booklet is in use as course material in engineering courses to foster innovation, it is also in use to support innovation contests. The innovation contests are announced and urge teams to sign up for a full day event. The participants are habitants from a particular place assigned to create ideas for a specific problem related to the place, or in some cases participants are students. All contests, though, have a company or organisation as the problem owner. The client presents the topic of the contest, describe the challenges and also whether they are looking for radically new concepts or improvements of a certain part. The client is also responsible to select the winning team. The participants, commonly, sign a nondisclosure agreement stating that the client owns the result.

The contests are outlined as a full-day workshop, with a handful numbers of teams with equally number of individuals in each team. Based on 25 innovation contests, some of the lessons learned are summarised in the following list:

1. The teams did not naturally used rough prototypes, e.g. sketches or mock-ups. Yet, those teams that did something like prototyping, e.g. used the whiteboards to draw something or used body language seem to have a more vigorous process for generating ideas and understanding concepts. Basically, supports have to nudge teams into communicative prototyping.

2. Contest prize with a monetary value does not motivate creativity and innovation, instead it blocks "thinking outside the box", the participants seem to develop concepts that align with their thoughts about the client's expectations instead of supporting radical thinking. Still, it attracted participants to sign up for the contests.

3. Teams that search for additional information had a better ground for framing and reframing the given design task. If so, the information search for should first be widening the insights about the task, the user or the context, and in later stages information should be focused to improve suggested solutions. Teams that gathered rich information tended to problematize more, thus they 
avoided fixations on one single concept already from the start. Basically, supports have to encourage broadening, or abstracting of the task.

These lessons learned have, in light of a shift into value creation (e.g. Ericson et al., 2015), served as a foundation to design, develop and implement a mobile supports toolbox to promote innovation in SMEs.

\section{Transferring lessons learned to promote small firms' innovation activities}

The challenge for the provision of a successful toolbox (see Figure 2) were, first to make it mobile. Going out to the SMEs is a necessity since they state that time is one large barrier for allocating time on new product development. Second, to make it enable learning and to practice theorizing in a fit-forpurpose approach, i.e. learning by doing. Third, to make it a support that could enable SMEs to work on their actual real-world problems, and not fictive ones just for the sake of learning.

The supports toolbox CBTL is thus an effort to package theory into a set of activities into a transportable prototyping lab. The rationale for a portable unit is to increase availability of the toolbox where it is needed. A university have the possibility to bring a team of motivated students to the company's facilities to provide external inspiration. Besides allowing swift insights into the company's operations and work procedures, this trains both students and companies in collaboration and innovation. Moreover, the approach to reach out and visit companies make it possible for more staff to participate, or at least, out of sheer curiosity, have the possibility to drop in to the activity.

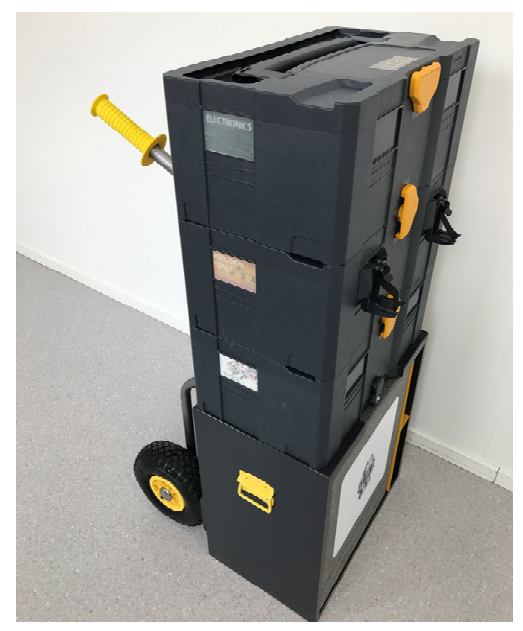

Figure 2. An overview picture of the mobile CBTL toolkit

Based on the lessons learned, as presented above (bullets 1-3), improvements to the setup where derived from piloting the CBTL use in industrial environments. The guiding principles for the CBTL clinics, e.g. experimental and learning workshops are:

- mobilise an external team,

- that the team orient themselves in a wider view of the problem,

- identifies and takes on the stakeholders' perspective,

- represents their insight into a first rough visualisation,

- learning about concepts and users by challenging the prototype,

- start reframing in several sets,

- and finally create a concept manifested in a physical form that can be communicated to someone outside the team.

The preparation of the CBTL clinic is important, hence depending on time frame the material (level and type) can be differently prepared. Also, the initial problem should be described with care. In this case the company could preferably present the design task as precise as they experience it. The problem definition (and/or problematizing of already defined problems) and reframing are part of the CBTL process hence ensuring that understanding of the situation will be present early on in the work. 
Design thinking is based upon elaborating with various types of prototyping (e.g. Dym et al., 2005; Brown, 2008; Dorst, 2011). This supports framing and reframing, accordingly train developers to change perspective and to see other dimensions of a task. Being able to express and share ideas among and between each other in a team are part of the core of collaboration, here making thinking visual (Casakin, 2005) is important. Communicative prototyping focus on rough, quick and simple expressions and representation, and the efforts are to visualise those hard ideas and thought that are explorative and more sensed than easily expressed. This act of simple prototyping should then correspond to the initial part of framing a problematic situation. In order to be able to reframe the situation of an engineering design task, another activity becomes more important, i.e. the team should address the function they want to achieve and create a test for that. By iterating between two categories of rough prototypes, i.e. one visualising the idea and one addressing critical functions, a frame and reframe-cycle can be achieved. The cyclic activities correspond also to e.g. Interpret-Ideate-Convey (Bergström, 2009) and Design-Build-Test (Dubberly, 2004). The first focus on exploration of what could be, and the latter focus on exploitation of what is already established. Used together such iterative activities support creation of new knowledge and confront of the current beliefs, i.e. frame and reframe several aspects. Since these iterative cyclic models are concentrated on internal communication they may guide innovation in some respects but there may be a need for some modification in order to reach external stakeholders that probably does not have the same understanding as the rest of the team. Such activity may also be based on a simple sequence, such as, design-build-test, but should be focused on what the team wants to communicate to external actors.

The CBTL clinics take inspiration from agile development, design thinking and communicative prototyping, and describes the steps:

1. Create - express ideas and assumptions by talking, show with hands, draw, or use other simple available props (as shown in Figure 3)

2. Build - develop functional but simple prototyping

3. Test - compare criteria from the Create stage with assessments or measures from testing

4. Learn - reflect and take a decision on next iteration

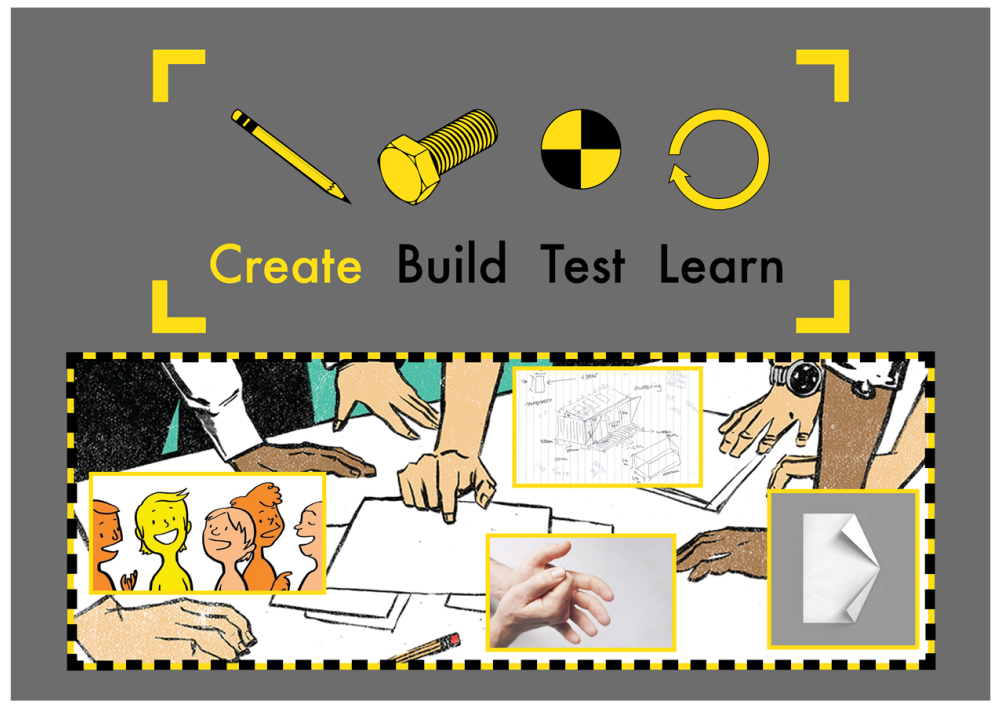

Figure 3. Presentation of the first step, as used in the clinics

Figure 3 exemplifies the presentation material that guides the explorative and learning activities in the clinics. The presentation of the process is low in details, thus making them function as quick guides rather than extensive lectures. The rational for providing overview and not detail is that CBTL clinics should be facilitated by a person skilled in the process. An iteration back to Create includes comparisons with the outcomes from Test, thus, in the second Create reframing is a key task. Hence, the format is based on agile sprints (approx. 0.5h-2h) containing the iterative CBTL activities. As a consequence, the first sprint may involve more Create that later sprints. 

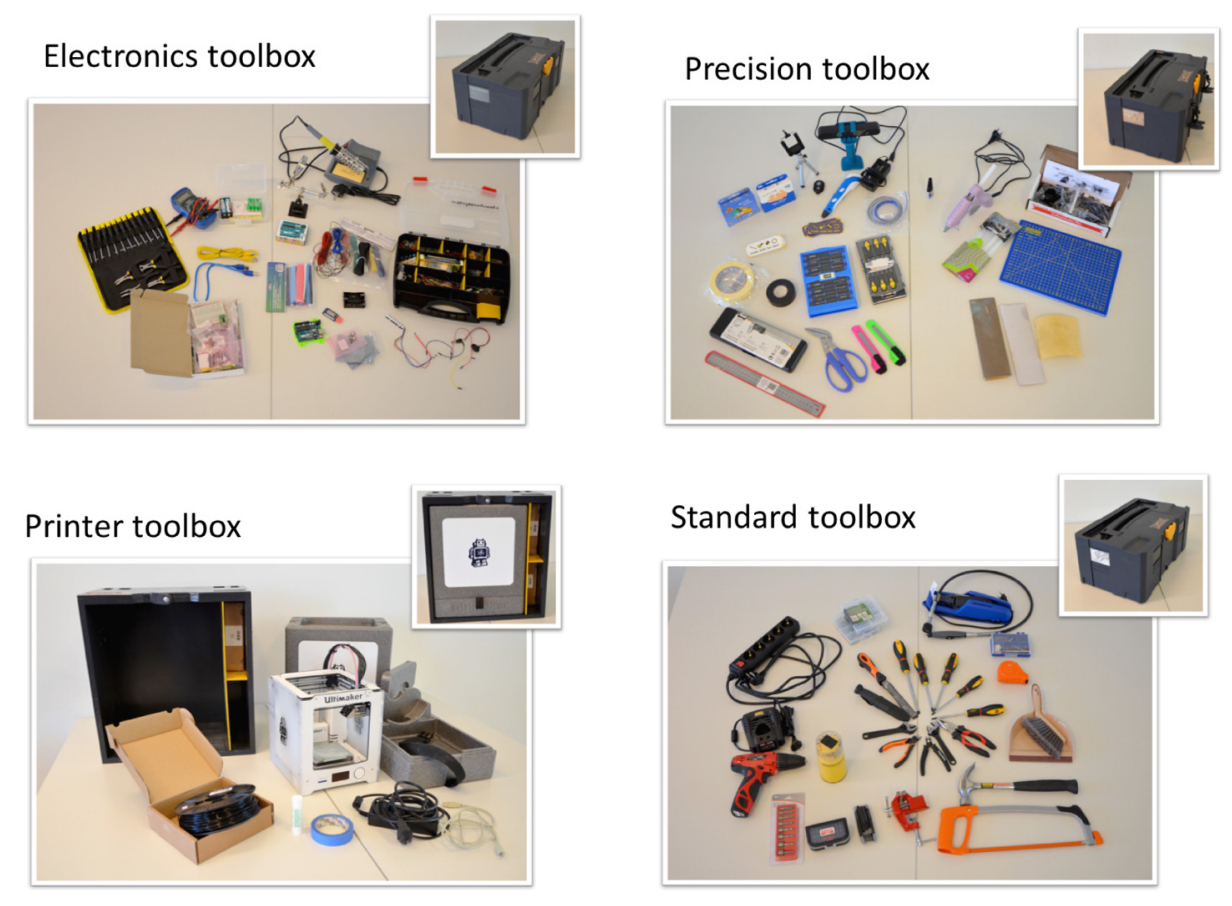

Figure 4. The mobile supports toolboxes

The mobile toolbox, see Figure 4, that enable CBTL clinics consists today of 4 units (1) a precision toolbox including for example a basic 3D scanner and 3D pen, but also tools for mock-ups in paper, (2) an electronics toolbox including for example open-source electronic Arduino sets, (3) Printer toolbox including an Ultimaker 3D printer and filaments, and (4) a standard toolbox, e.g. electric screwdriver, hammer, saw and other hand held tools that are useful in building prototypes of plastic or wood. Additional equipment will be a portable laser cutting tool box to enable quicker and more precise prototyping in paper, wood and plastic.

The general agenda for a CBTL clinic, starts with an intro; both to get familiar with each other as participants and with the problem owner's facilities or environment, in some cases a short study visit is done. The introduction is followed by a presentation of methods, the challenge and criteria for evaluation. In relation to this also the CBTL toolbox's units, in Figure 4, is presented and questions about how to use the tools are addressed. In the Create activities, particularly the standard toolbox unit together with paper and cardboard support exploration of the design task by simple prototyping. In the case of an engineering design task, the main activity here is to explore basic principles and background and giving them physical expressions, by doing so the team can become aware of their assumptions. The Build activities emphasises demonstration of concepts, and in engineering design the mechanical principles are sought to undergo a systematic exploration to understand and define plausible solutions. Here, the precision toolbox unit is often introduced by the teams. Test activities is often overlapping the demonstrations and is a way to add to the demonstrated solutions, e.g. refine, improve, reconstruct, reframe. The teams compare the outcomes with the criteria from Create activities. Testing include thereby also the input for the emergence of new prototypes. The precision tools and electronic tools are commonly supporting these activities, while after the first iteration when concepts are more mature. The printer unit and the laser cutter unit also enable teams to elaborate and learn. The Learn activity is a zooming out, taking a step back step to reflect on the process. Those dialogues are needed as an input to a new iteration starting with Create. The rule of maturity, i.e. when no new ideas adds to the solution, settle when it is time to break the iteration and start a new loop. Of course, the CBTL clinics may include other, or additional, toolbox units as well, e.g. when the design task involves any specific principles or technology that need to be expressed in the prototyping activities. 
The toolbox units have been collected carefully based on the process of the clinic, thus just providing a set of tools is not the point here. CBTL is built upon a four-step iterative action cycle for prototyping, but it also requires a facilitation of an innovation coach. One way of provoking a change in attitude among SMEs relates to the facilitation and coaching of an external resource, having the ability to lead a team into a new way of thinking. The importance of interacting and playing with prototypes encourage conversations, collaborations and argumentations which provide, not only the means for examining design problems and evaluating solutions, but also an inspiration for new product development.

\section{Does CBTL work? What more needs to be done?}

This paper describes the rationale for the development of a supports toolbox and also a description for how it is facilitated to sustain innovation in SMEs. The rationale for the development of the toolbox is based on several years of experimenting and implementing innovation supports in companies and organisation. The CBTL clinics as such has been implemented in a few empirical cases, so conclusions on its effects are not drawn. Yet, when compared with the previous innovation contests, we see a positive result. First, focusing on availability seem to be a resource efficient choice. Bringing a prototype lab to the company premises when doing a specific effort like this seem better than trying to bring companies into the university. Secondly, based on the tentative results of this study, as well as prior research and literature in the area, we suggest that the starting point for development is the team members motivation and understanding of how to solve the problem at hand. We found that the simultaneous doing and reflecting upon innovation activities could have progressed and increased the understanding of the design task. The communicative prototypes provide a focused dialogue in the teams, at the same time different perspectives on the task became more visible. Thus, it seemed that the teams more promptly could pose questions that progressed a shared vision of the task. Tentatively, the suggested approach may strengthen theory on communicative prototyping as a key to a better innovation processes. Further we suggest methods to quickly and dynamically transforming the understanding in the team while maintaining motivation, e.g. adding to participants' understanding helps to maintain motivation. A factor for success is to use CBTL in sequence and repeat the loop (in other workshop formats we often we see only one of these loops repeat in an entire workshop) which will contribute to a new understanding (framing and reframing) to a completely different extent than before.

In the case of small firms' innovation, a substantial burden of the work will be on an external facilitator. This ability or experiences are commonly not part of small manufacturing firms core competences, which means that training will be vital but also a possibility to develop procedures like this to efficiently utilize external competence, like for example students. Allocating time for issues like creativity and innovative thinking is another limited resource in small firms. Therefore, SMEs often insists on before handed knowing the outcome of these activities. This is, of course, a pitfall since innovation actually means to investigate an unknown situation. Here, we suggest more studies on practical activities in collaboration with SMEs since these interactions enable changes in attitudes. Prototyping that are aimed towards functional testing can be time consuming even for skilled persons. The CBTL toolkit included a 3D printer which may be too heavy weighted for one-day clinics if not acquainted with the technology before, yet valuable in other cases. We found cardboard a good material in order to create quick and simple prototypes. Although, investigations of what other materials that could be used are suggested.

\section{Acknowledgements}

Financing for the Innovations \& Industrial Internet -project (I3) from the EU program INTERREG North 2014 2020 that aims to support cross-border collaboration to strengthen competitiveness and attractiveness within the area of northern Sweden, northern Finland, northern Norway and Sápmi are gratefully acknowledged. Also, EIO - Effective Innovation and Organization (Area of excellence in research and innovation) and TARGET, Making Regional Manufacturing Globally Competitive and Innovative, financed by the Northern Periphery and Arctic Programme 2014-2020 are acknowledged.

\section{References}

Bergström, M. (2009), Probing for innovation, PhD Thesis, Luleå University of Technology. 
Bergström, M., Ericson, Å. and Törlind, P. (2010), 4I4I: Four I:s for Innovation: a book with easy to use methods and ideas to foster innovative product development, 2nd ed., Luleå, ISBN: 978-91-7439-148-0.

Brown, T. (2008), "Design thinking”, Harvard Business Review, Vol. 86 No. 6, pp. 84-92.

Cantamessa, M. (2005), "Competencies growth in manufacturing firms engaged in product development-An empirical study", Proceedings of 15th International Conference on Engineering Design, ICED 05, Melbourne, Australia, pp. 1-10.

Casakin, H. (2005), "Design Aided by Visual Displays: A Cognitive Approach", The Journal of Architectural and Planning Research, Vol. 22 No. 3, pp. 250-265.

Christensen, C.M., Raynor, M.E. and McDonald, R. (2015), “What is disruptive innovation?”, Harvard Business Review, pp. 44-53.

Cox, C., Wenngren, J., Holmqvist, J. and Ericson, Å. (2014), "Tendencies toward problem-setting and problemsolving: A study of operations derived from motivation strategies", International Journal of Technology, Knowledge and Society, Vol. 10 No. 2.

Dorst, K. (2011) “The core of ‘design thinking' and its application”, Design Studies, Vol. 32 No. 6, pp. 521-532. https://doi.org/10.1016/j.destud.2011.07.006

Dubberly, H. (2004), How do you design? A compendium of models, Dubberly Design Office, San Francisco, CA.

Dym, C.L., Agogino, A.M., Eris, O., Frey, D.D. and Leifer, L.J. (2005), "Engineering design thinking, teaching, and learning”, Journal of Engineering Education, Vol. 94 No. 1, pp. 103-120. https://doi.org/10.1002/j.21689830.2005.tb00832.x

Ericson, A. and Törlind, P. (2013), "A deep dive into creative thinking: the now-wow-how framework", Proceedings of International Conference on Engineering Design ICED13, Seoul, Korea, pp. 337-346.

Ericson, Å., Håkansson, A. and Öhrling, D. (2012), "Revisiting prototyping: learning in early design”, Proceedings of the 12th International Design Conference, DESIGN 2012, Dubrovnik, Croatia, pp. 2045-2052.

Ericson, Å., Johansson, C. and Nergård, H. (2015), "Manufacturing knowledge: Going from production of things to designing value in use", Intelligent Decision Technologies, Vol. 9, pp. 79-89. https://doi.org/10.3233/IDT140207

Howard, T.J., Culley, S.J. and Dekoninck, E. (2008), "Describing the creative design process by the integration of engineering design and cognitive psychology literature", Design Studies, Vol. 29 No. 2, pp. 160-180. https://doi.org/10.1016/j.destud.2008.01.001

Jacoby, R. and Rodriguez, D. (2007), "Innovation, growth, and getting to where you want to go", Design Management Review, Vol. 18 No. 1, pp. 10-15. https://doi.org/10.1111/j.1948-7169.2007.tb00067.x

Khandani, S. (2005), "Engineering design process: Education Transfer Plan", IISME/Solectron Corporation, Milpitas, California.

Löfqvist, L. (2014), Product innovation in small established enterprises: Managing processes and resource scarcity. $\mathrm{PhD}$ thesis, KTH Royal Institute of Technology.

Örtqvist, D. (2015), Näringslivsutveckling i Nordprogramområdet, en analys av tillväxtambitioner, samverkan och export, Länsstyrelsen i Norrbottens län, Luleå.

Sheppard, S., Jenison, R., Agogino, A., Brereton, M., Bocciarelli, L. et al. (1997), "Examples of freshman design education", International Journal of Engineering Education, Vol. 13 No. 4, pp. 248-261.

Steinert, M. and Leifer, L.J. (2012), “'Finding One's Way': Re-Discovering a Hunter-Gatherer Model based on Wayfaring”, International Journal of Engineering Education, Vol. 28 No. 2, p. 251.

Wenngren, J. (2016), Team activities in concept development: Addressing open-ended problems, PhD thesis, Luleå University of Technology.

Yang, M.C. (2005), “A study of prototypes, design activity, and design outcome”, Design Studies, Vol. 26 No. 6 , pp. 649-669. https://doi.org/10.1016/j.destud.2005.04.005

Dr. Johan Lugnet, Senior Lecturer

Luleå University of Technology, Information Systems

Luleå University of Technology, 97187 Luleå, Sweden

Email: johan.lugnet@1tu.se 